\title{
Cardiac abnormalities in familial palmoplantar keratosis
}

\author{
N PROTONOTARIOS, A TSATSOPOULOU, P PATSOURAKOS, \\ D ALEXOPOULOS, P GEZERLIS, S SIMITSIS, G SCAMPARDONIS
}

From the Department of Cardiology, 401 Army General Hospital, Athens, Greece

SUMMARY Cardiac abnormalities were identified in patients with familial palmoplantar keratosis. All of them were descended from families on the Greek island of Naxos. Four families were studied and nine cases of palmoplantar keratosis were identified; seven of them showed symptoms and signs of heart disease. Cardiomegaly on chest $x$ ray and electrocardiographic abnormalities were common findings. Three cases had episodes of ventricular tachycardia and a fourth patient died suddenly. All patients with cardiac signs and symptoms showed echocardiographic enlargement of the right ventricle and a right ventricular band; in three the left ventricle was also affected.

Several forms of hereditary palmoplantar keratosis are recognised in Mediterranean countries. In Greece the most common form is Meleda disease. ${ }^{12}$

Because recurrent ventricular tachycardia developed in two young patients with palmoplantar keratosis from the Greek island of Naxos we sought evidence of cardiac abnormalities in families on this island that included members with this dermatosis.

\section{Patients and methods}

We identified four families from the Greek island of Naxos that included known cases of palmoplantar keratosis (fig 1). All available family members underwent clinical examination including a detailed history of cardiac events, electrocardiography at rest, and chest radiography. The histories of those who had died were supplied by their families. Patients with palmoplantar keratosis and all other living family members with cardiac abnormalities were examined by echocardiography. We used an Aloka apparatus model SSD 720 and a $3 \mathrm{mHz}$ mechanical transducer to obtain parasternal long and short axis views and apical and subxiphoid two and four chamber views. Right and left ventricular dimensions were measured on $M$ mode echocardiograms obtained during diastole. ${ }^{3}$ A mean (SD) right to left ventricular diameter ratio of $0.33(0.06)$ was regarded as normal. ${ }^{4}$

Requests for reprints to Dr N Protonotarios, 8 Elia Zervou Street, Athens 111 44, Greece.

Accepted for publication 24 June 1986

\section{Results}

PATIENTS WITH PALMOPLANTAR KERATOSIS

We identified nine cases, six male and three female (mean age 24.5 (range 7-41) years), of palmoplantar keratosis (table 1).

\section{Extracardiac anomalies}

All patients had pale yellow diffuse palmar and plantar keratoses with clear borders that had appeared between the sixth and twelfth month. They all had dense, rough, dull, and bristly scalp hair resembling steel wire (fig 2). Six patients had short fingers and four of them also had curved nails; their hands or arms were generally rather small.

\section{Cardiac history}

Six patients gave a history of paroxysmal tachycardia, palpitation, or syncope (table 1). Three of them (cases 1, 3, and 4) had documented episodes of severe ventricular tachycardia. Patients 1 and 3 who had recurrent ventricular tachycardia that was resistant to medical treatment were initially regarded as cases of Ebstein's anomaly. In patient 1 the diagnosis of Ebstein's anomaly had led to investigation by cardiac catheterisation and replacement of the tricuspid valve. In patient 3 Ebstein's anomaly was excluded by cardiac catheterisation, coronary arteriography, and electrophysiological study at the National Institutes of Health, Bethesda, Maryland. There was evidence of right ventricular enlargement, segmental wall motion abnormalities of both 
ventricles, and recurrent drug resistant ventricular tachycardia with left bundle branch block configuration. Biventricular endomyocardial biopsy showed hypertrophy of myocardial cells without fibrosis or cellular infiltration.

\section{Cardiac signs}

Four patients had a fourth heart sound and in another two a 2/6-3/6 high pitched midsystolic murmur was heard over the lower left sternal border. In patient 1 the signs were that an atrioventricular prosthesis was functioning normally (table 1 ).

\section{Electrocardiographic findings}

The electrocardiogram was abnormal in all seven patients (table 2). Patients 1 and 5 had right and left abnormal QRS axis deviation respectively. Two patients had right bundle branch block and in the other five the QRS complex was more than $100 \mathrm{~ms}$ wide, which is consistent with an intraventricular conduction defect. Moreover, all seven patients had inverted $T$ waves in the precordial leads; in the youngest patient (patient 2) $T$ wave inversion in leads V1 to V3 was regarded as normal. Abnormal Q waves were present in three patients (cases 5, 6, and

Table 1 Clinical data on 9 patients with palmoplantar keratosis

\begin{tabular}{|c|c|c|c|c|c|c|c|}
\hline Case No & $\begin{array}{l}\text { Age } \\
(y r)\end{array}$ & Sex & $\begin{array}{l}\text { Scalp hair } \\
\text { abnormalities }\end{array}$ & Brachydactyly & Curved nails & Cardiac signs & $\begin{array}{l}\text { Cardiac events } \\
\text { (age at onset) }\end{array}$ \\
\hline $\begin{array}{l}1 \\
2 \\
3 \\
4 \\
5 \\
6 \\
7 \\
8 \\
9\end{array}$ & $\begin{array}{r}26 \\
7 \\
32 \\
17 \\
26 \\
19 \\
17 \\
41 \\
36\end{array}$ & $\begin{array}{l}M \\
M \\
M \\
M \\
M \\
M \\
F \\
F \\
F\end{array}$ & $\begin{array}{l}+ \\
+ \\
+ \\
+ \\
+ \\
+ \\
+ \\
+ \\
+\end{array}$ & $\begin{array}{l}+ \\
+ \\
+ \\
+ \\
+ \\
+ \\
+ \\
+\end{array}$ & $\begin{array}{l}+ \\
\overline{+} \\
- \\
- \\
\overline{+} \\
\overline{+}\end{array}$ & $\begin{array}{l}\text { AVP } \\
\text { Normal } \\
\text { S4 } \\
\text { S4 } \\
\text { S4 } \\
\text { SM } \\
\text { SM } \\
\text { S4 } \\
\text { Normal }\end{array}$ & $\begin{array}{l}\text { Recurrent VT (17 yr) } \\
\text { Asymptomatic } \\
\text { Recurrent VT }(28 \mathrm{yr}) \\
\text { VT } \times 2(17 \mathrm{yr}) \\
\text { Syncope } \times 3(21 \mathrm{yr}) \\
\text { Asymptomatic } \\
\text { Syncope } \times 1(16 \mathrm{yr})^{\star} \\
\text { Palpitation }(31 \mathrm{yr}) \\
\text { Asymptomatic }\end{array}$ \\
\hline
\end{tabular}

AVP, atrioventricular prosthesis; S4, fourth heart sound; SM, systolic murmur; VT, ventricular tachycardia.

^The patient died suddenly a few months later.

Family A

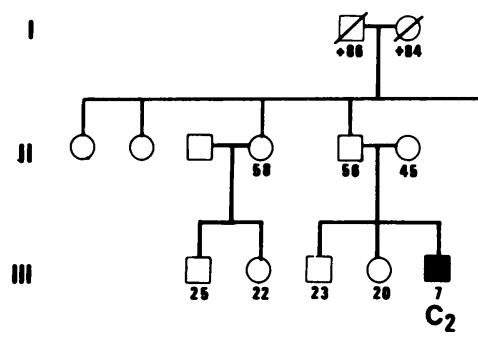

IV
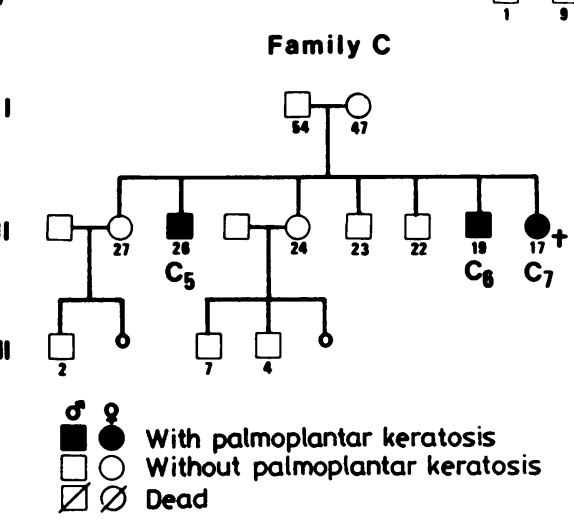
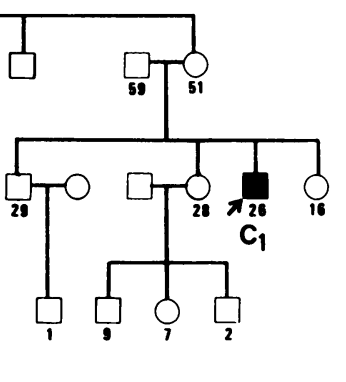

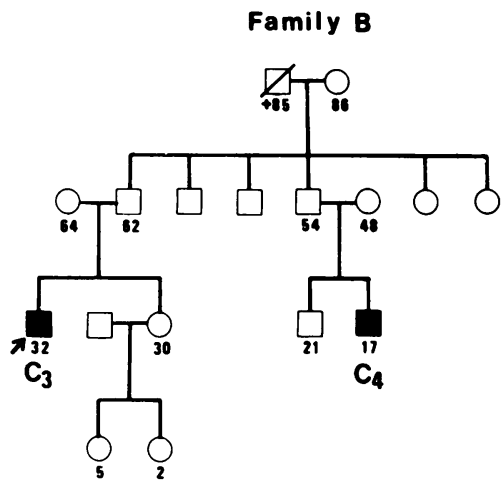

Family D

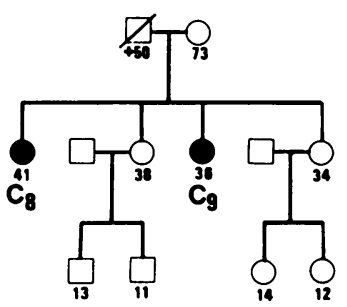

Fig 1 Pedigrees of four families from the Greek island of Naxos. Case (C) numbers refer to patients with palmoplantar keratosis in text and in table 1. Individual ages in 1985, or age at time of death are given.

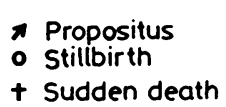




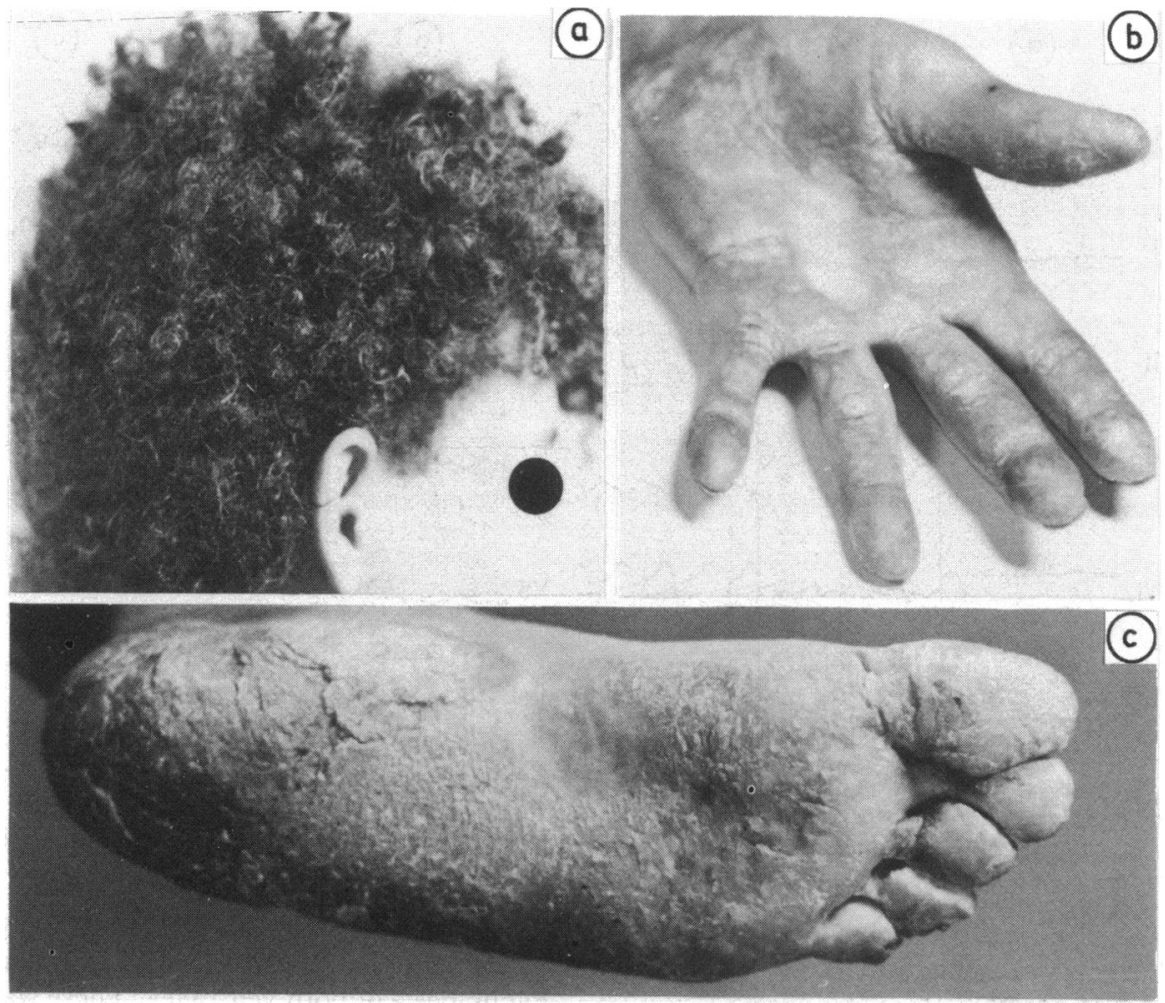

Fig 2 Hair, palms, and soles in palmoplantar keratosis. (a) The scalp hair was dense, rough, and bristly. (b) Keratosis of the palmar folds and the medial sides of the fingers. (c) Keratosis uniformly covering the soles of the feet.

8). Patients 1,7 , and 8 had low voltage electrocardiograms ( $R$ wave $<0.5 \mathrm{mV}$ in limb leads and $1 \mathrm{mV}$ in the precordial leads).

\section{Arrhythmias}

All patients were in normal sinus rhythm, except patient 1 who had atrial fibrillation. In six patients there were frequent extrasystoles, mainly of right ventricular origin. In patient 8 , who complained of palpitation, no ventricular extrasystoles were recorded at rest. Episodes of ventricular tachycardia of left bundle branch block configuration (fig 3) were recorded in three cases (table 3); a fourth patient (case 7) with ventricular extrasystoles died suddenly.

\section{Chest radiography}

The heart size was increased (cardiothoracic ratio $>0.50$ ) in seven cases (table 2). In patient 1 the

Table 2 Electrocardiographic, radiographic, and echocardiographic findings in 9 patients with palmoplantar keratosis

\begin{tabular}{|c|c|c|c|c|c|c|c|c|c|}
\hline \multirow[b]{2}{*}{ Case No } & \multirow[b]{2}{*}{$\begin{array}{l}\text { Cardiac } \\
\text { rhythm }\end{array}$} & \multicolumn{4}{|c|}{$Q R S T$ electrocardiogram } & \multirow[b]{2}{*}{$\begin{array}{l}X \text { ray } \\
C T \text { ratio }\end{array}$} & \multicolumn{3}{|c|}{ Echocardiography } \\
\hline & & $\begin{array}{l}\text { QRS } \\
\text { axis }\end{array}$ & $\underset{\text { (ms) }}{Q R S}$ width & $\begin{array}{l}\text { QRS } \\
\text { configuration }\end{array}$ & $\begin{array}{l}\text { Inverted } \\
T \text { waves }\end{array}$ & & $\begin{array}{l}R V E D D \\
(\mathrm{~mm})\end{array}$ & $\underset{(\mathrm{mm})}{L V E D D}$ & $\begin{array}{l}R V: L V \\
\text { ratio }\end{array}$ \\
\hline $\begin{array}{l}1 \\
2 \\
3 \\
4 \\
5 \\
6 \\
7 \\
8 \\
9\end{array}$ & $\begin{array}{l}\text { AF, ES, VT } \\
\text { NSR } \\
\text { NSR, ES, VT } \\
\text { NSR, ES, VT } \\
\text { NSR, ES } \\
\text { NSR, ES } \\
\text { NSR, ES } \\
\text { NSR } \\
\text { NSR }\end{array}$ & $\begin{array}{r}+135 \\
+90 \\
-30 \\
-30 \\
-75 \\
+100 \\
-30 \\
-30 \\
+60\end{array}$ & $\begin{array}{r}140 \\
80 \\
120 \\
160 \\
120 \\
140 \\
120 \\
120 \\
100\end{array}$ & $\begin{array}{l}\text { IVCD } \\
\text { Normal } \\
\text { IVCD } \\
\text { RBBB } \\
\text { IVCD } \\
\text { RBBB } \\
\text { IVCD } \\
\text { IVCD } \\
\text { Normal }\end{array}$ & $\begin{array}{l}\text { V1-V6 } \\
\text { V1-V3 } \\
\text { V1-V4 } \\
\text { V1-V4 } \\
\text { V1-V6 } \\
\text { V1-V6 } \\
\text { V1-V6 } \\
\text { V1-V4 } \\
-\end{array}$ & $\begin{array}{l}0.68 \\
0.50 \\
0.56 \\
0.52 \\
0.64 \\
0.51 \\
0.61 \\
0.56 \\
0.42\end{array}$ & $\begin{array}{l}80 \\
12 \\
34 \\
32 \\
42 \\
43 \\
40 \\
36 \\
11\end{array}$ & $\begin{array}{l}37 \\
32 \\
43 \\
42 \\
63 \\
48 \\
60 \\
51 \\
40\end{array}$ & $\begin{array}{l}2 \cdot 16 \\
0 \cdot 37 \\
0 \cdot 79 \\
0 \cdot 76 \\
0 \cdot 67 \\
0 \cdot 90 \\
0 \cdot 67 \\
0 \cdot 70 \\
0 \cdot 28\end{array}$ \\
\hline
\end{tabular}

AF, atrial fibrillation; CT, cardiothoracic; IVCD, interventricular conduction defect; LV, left ventricle; LVEDD, left ventricular end diastolic diameter; NSR, normal sinus rhythm; ES, estrasystole; RBBB, right bundle branch block; RV, right ventricle; RVEDD, right ventricular end diastolic diameter; VT, ventricular tachycardia. 
(a)
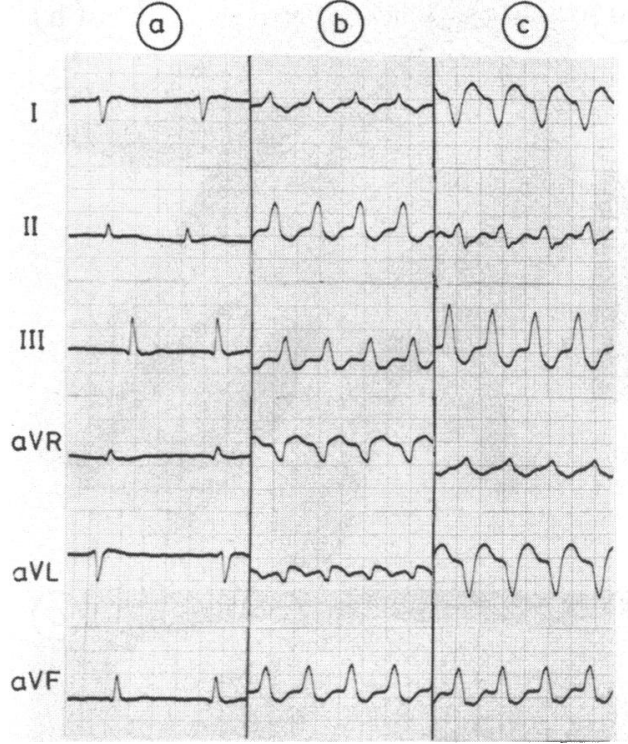

(a)

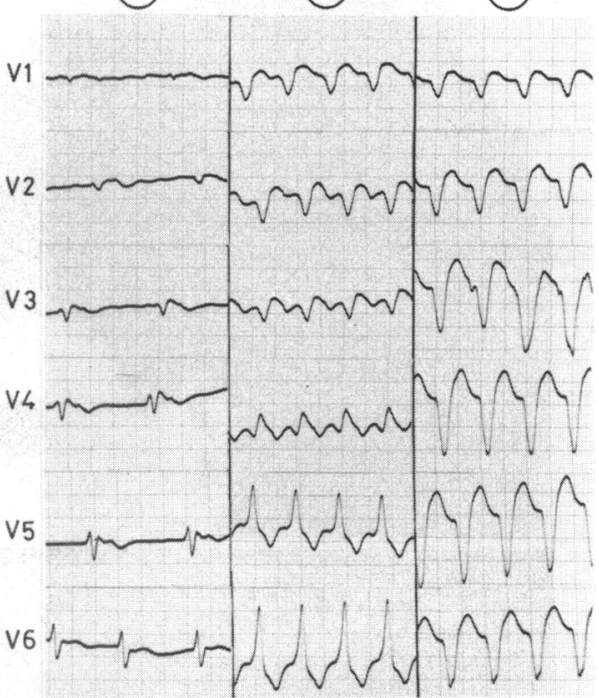

(c)

Fig 3 Normal electrocardiogram ( $a$ ) and two episodes of ventricular tachycardia ( $b$ and $c$ ) in patient 1 (single channel recorder). In (a) there was a $Q R S$ axis of $>135 \mathrm{ms,} Q R S$ prolongation, low voltage, and $T$ wave inversion in the precordial leads. In both (b) and (c) the ventricular tachycardia rate is 160 beats per minute and the $Q R S$ axes were $>75 \mathrm{~ms}$ and $>135 \mathrm{~ms}$ respectively.

cardiac silhouette was oversized, with gross right atrial and right ventricular dilatation. Pulmonary vasculature was normal.

\section{Echocardiography}

In seven of the nine patients the right ventricular end diastolic diameter was enlarged and the ratio of the diameters of right and left ventricles was increased (range 0.67-2.16) (table 2). Two of them (cases 5 and 7) also had left ventricular dilatation with diffuse hypokinesia of both ventricles. There was moderate hypokinesia of the left ventricle in patient 8 in whom the left ventricular end diastolic diameter was in the upper limit of normal. In patient 1 , who had severe right ventricular hypokinesia, the right ventricle and right atrium were grossly enlarged. The inter-
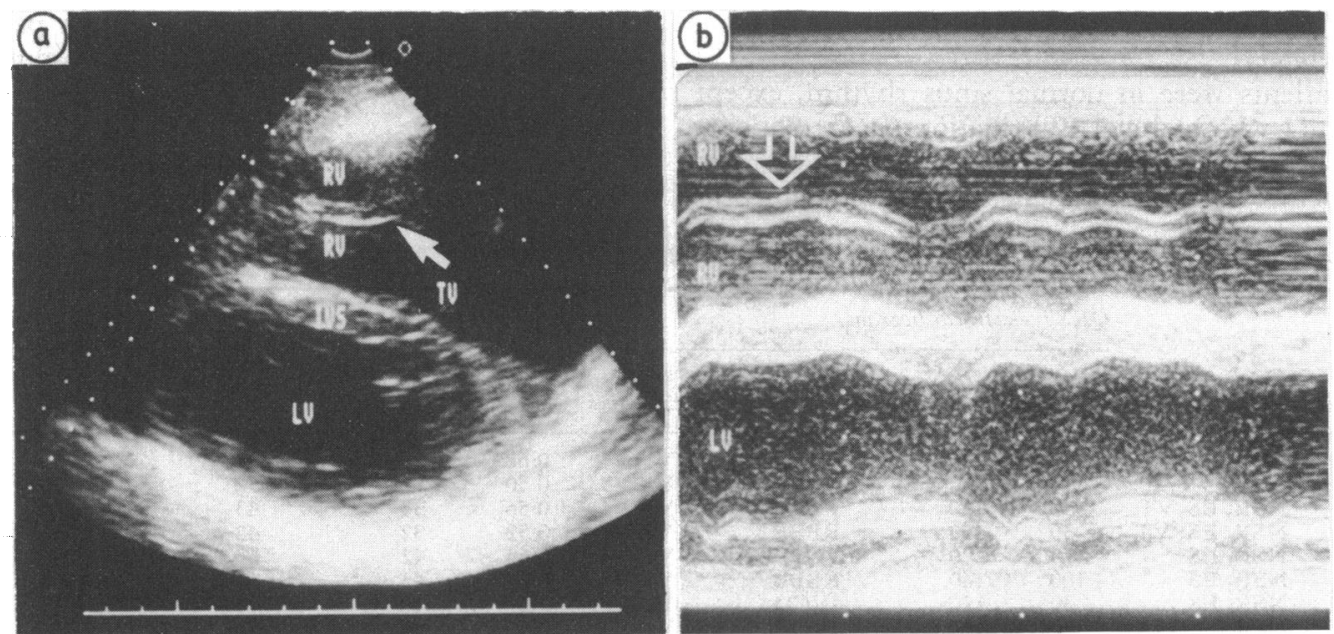

Fig 4 Cross sectional (a) and $M$ mode (b) images of patient 4 in the modified long axis parasternal view. An echodense muscular type band (arrows) parallel to the interventricular septum (IVS) is present in the right ventricle $(R V)$. LV, left ventricle; TV, tricuspid valve. 
Table 3 Documented episodes of VT in three of our patients

\begin{tabular}{|c|c|c|c|c|c|c|}
\hline \multirow[b]{2}{*}{ Case No } & \multirow[b]{2}{*}{$\begin{array}{l}\text { Age (yr) at } \\
\text { episode }\end{array}$} & \multirow[b]{2}{*}{ Symptoms } & \multicolumn{3}{|c|}{ Electrocardiogram during $V T$} & \multirow[b]{2}{*}{$\begin{array}{l}\text { Termination } \\
\text { of } V T\end{array}$} \\
\hline & & & $\begin{array}{l}Q R S \\
\text { axis (ms) }\end{array}$ & $\begin{array}{l}\text { QRS } \\
\text { configuration }\end{array}$ & $\begin{array}{l}\text { Rate } \\
\text { (beats per min) }\end{array}$ & \\
\hline 3 & $\begin{array}{l}26 \\
28\end{array}$ & Palpitation, dizziness & +135 & LBBB & 150 & DC shock \\
\hline & $\begin{array}{l}28 \\
28\end{array}$ & $\begin{array}{l}\text { Palpitation, syncope } \\
\text { Palpitation, dizziness }\end{array}$ & $\begin{array}{l}+75 \\
+75\end{array}$ & $\begin{array}{l}\text { LBBB } \\
\text { LBBB }\end{array}$ & 260 & DC shock \\
\hline & 29 & Palpitation, dizziness & +120 & LBBB & 150 & DC shock \\
\hline 4 & 17 & Palpitation, syncope & +75 & LBBB & 210 & Lignocaine \\
\hline & 17 & Palpitation, dizziness & +75 & LBBB & 140 & Lignocaine \\
\hline
\end{tabular}

LBBB, left bundle branch block; VT, ventricular tachycardia.

ventricular septum moved paradoxically in two patients (cases 1 and 5) and was hypokinetic in another two (cases 7 and 8). Neither right nor left ventricular hypertrophy was seen. In all the cases with an enlarged right ventricle there was an echo dense muscular band that originated from the right apex and ran parallel to the interventricular septum (fig 4). Mitral valve prolapse was found in one patient (case 2).

\section{FAMILY MEMBERS WITHOUT PALMOPLANTAR KERATOSIS}

We were able to examine 40 members of the study families who did not have palmoplantar keratosis (fig 1). Except for a case of mitral valve prolapse none had cardiac abnormalities. None of these who had died was reported to have died suddenly or to have had skin lesions or heart disease.

\section{Discussion}

\section{PALMOPLANTAR KERATOSIS}

Palmoplantar keratosis is a familial ectodermal defect characterised by hyperkeratosis of the palms and soles. ${ }^{5}$ It is occasionally seen in association with brachydactyly or nail anomalies. ${ }^{2}$ Meleda disease typically affects not only the palms and soles but also the backs of the hands and feet and is often associated with short cone shaped fingers and nail abnormalities. (koilonychia, pachyonychia) but not scalp hair abnormalities. ${ }^{26}$ The only palmoplantar keratosis with scalp hair anomalies (similar to the ones noted in our cases) is leuconychia totalis. ${ }^{7}$ Palmoplantar keratosis has been reported to occur in association with dental lesions, deafness, ophthalmic anomalies, and oligophrenia, ${ }^{267}$ but not cardiac abnormalities. Our pedigree studies suggested that this is an autosomal recessive trait (fig 1). All four families came from the island of Naxos but many members were born and are living in several parts of Greece.

\section{CARDIAC DISORDERS}

The occurrence of strikingly similar cardiac abnor- malities in most of our patients with palmoplantar keratosis cannot be regarded as a coincidence. The common cardiac disorder shared by our patients were electrocardiographic abnormalities, cardiomegaly, and echocardiographic evidence of predominantly right ventricular abnormalities. The electrocardiographic disorders noted in our patients included intraventricular conduction delays, $T$ wave inversion in the precordial leads, abnormal $Q$ waves, low voltage, and also arrhythmias of ventricular origin (ventricular extrasystoles, recurrent ventricular tachycardia with left bundle branch block configuration). The echocardiographic abnormalities consisted of cardiac enlargement mainly of the right ventricle, wall motion abnormalities, and an echodense muscular type band originating from the right apex.

Possible differential diagnoses of heart disease in our patients are dilated cardiomyopathy and arrhythmogenic right ventricular dysplasia.

The age and sex of our patients and the electrocardiographic disorders, right ventricular enlargement, and recurrent episodes of ventricular tachycardia accord with the features of dilated cardiomyopathy predominantly affecting the right ventricle. ${ }^{89}$ But there was no clinical evidence of heart failure in any of our patients. Similarly, paradoxical interventricular septal motion was found in only two of our patients but it was a common echocardiographic feature in all cases of dilated cardiomyopathy of the right ventricle described by Fitchett et al. ${ }^{9}$ Also the prominent right ventricular band found in several of our patients is uncommon in dilated cardiomyopathy. Paraseptal structures were seen in the right ventricle of most patients with dilated cardiomyopathy who were candidates for cardiac transplantation. ${ }^{10} \mathrm{~A}$ biventricular endomyocardial biopsy performed on patient 3 showed no evidence of active inflammation or fibrosis. Necropsy was not performed on patient 7 who died suddenly on the island of Nexos.

The syndrome of arrhythmogenic right ventricu- 
lar dysplasia consists of isolated right ventricular myopathy and recurrent ventricular tachycardia. ${ }^{411} 12$ Three of our patients (cases 1, 3, and 4) developed the principal features of this syndrome. They were young men who presented with recurrent ventricular tachycardia of left bundle branch block configuration. The resting electrocardiograms showed $T$ wave inversion in the anterior precordial leads and differing degrees of delayed right ventricular activation. Ventricular post-excitation waves were seen in V1 and V2 on the electrocardiogram of patient 4 despite the recording being at normal sensitivity. Echocardiography showed isolated dilatation of the right ventricle with an increase in the ratio of right to left ventricular diameters. Right ventricular enlargement was also seen in the other four patients with cardiac signs and symptoms. Three of these had left ventricular dysfunction at rest. Although the left ventricular dysfunction accompanying arrhythmogenic right ventricular dysplasia was easily uncovered by exercise, ${ }^{13}$ its presence at rest was reported with variable frequency..$^{412}$

The familial occurrence of right ventricular dilated cardiomyopathy ${ }^{14}$ and arrhythmogenic right ventricular dysplasia has been reported. ${ }^{15}$ In each report only one family was identified and the patients were siblings of the same family.

Patient 1 may have had Ebstein's anomaly with additional myocardial dysplasia, as shown by the huge right ventricle, the prominent right ventricular band, and recurrent ventricular tachycardia. ${ }^{16} 17$

We believe that our cases have a familial or possibly an autosomal recessive hereditary disorder that is characterised by both palmoplantar keratosis and right ventricular dysplasia causing potentially lethal arrhythmias. Further studies are in progress.

\section{References}

1 Photinos MP, Souvatzides A. Trois cas de maladie de Méléda (premiers cas observés en Grèce). Bull Soc Franc Derm Syph 1939;49:177-80.

2 Franceschetti AT, Reinhart V, Schnyder VW. Meleda disease. $f$ Genet Hum 1972;20:267-96.

3 Sahn DJ, De Maria A, Kisslo J, Weyman A, and the Committee on M-mode Standardisation of the Amer- ican Society of Echocardiography. Recommendations regarding quantitation in $\mathrm{M}$-mode echocardiography: results of a survey of echocardiographic measurements. Circulation 1978;58: 1072-83.

4 Marcus FI, Fontaine GH, Guiraudon G, et al. Right ventricular dysplasia: a report of 24 adult cases. Circulation 1982;65:384-98.

5 Fred HL, Gieser RG, Berry WR, Eiband JM. Keratosis palmaris et plantaris. Arch Intern Med 1984;113: 866-71.

6 Brambila L, Pigatto PD, Boneschi V, Altomare GF, Finzi AF. Unusual cases of Meleda keratoderma treated with aromatic retinoid etretinate. Dermatologica 1984;168:283-6.

7 Crosti C, Sala F, Bertani E, Gasparini G, Menni S. Leuconychia totalis and ectodermal dysplasia. Report of 2 cases. Ann Dermatol Venereol 1983;110:617-22.

8 Goodwin JF. The frontiers of cardiomyopathy. $\mathrm{Br}$ Heart $\mathcal{f}$ 1982;48:1-18.

9 Fitchett DH, Sugrue DD, MacArthur CG, Oakley CM. Right ventricular dilated cardiomyopathy. $\mathrm{Br}$ Heart $\mathcal{F}$ 1984;51:25-9.

10 Keren A, Billingham ME, Popp RL. Echocardiographic recognition of paraseptal structures. $\mathcal{F}$ Am Coll Cardiol 1985;6:913-9.

11 Rossi P, Massumi A, Gillette P, Hall RJ. Arrhythmogenic right ventricular dysplasia: clinical features, diagnosis techniques, and current management. $\mathrm{Am}$ Heart $\mathcal{F}$ 1982;103:415-20.

12 Fontaine G, Frank R, Tonet JL, et al. Arrhythmogenic right ventricular dysplasia: a clinical model for the study of chronic ventricular tachycardia. $\mathcal{F p n ~ C i r c ~} \mathcal{F}$ 1984;48:515-38.

13 Manyari DE, Klein GJ, Gulamhusein S, et al. Arrhythmogenic right ventricular dysplasia: a generalized cardiomyopathy? Circulation 1983;2:251-7.

14 Ibsen HHW, Baandrup V, Simonsen EE. Familial right ventricular dilated cardiomyopathy. $\mathrm{Br}$ Heart $\mathcal{f}$ 1985;54:156-9.

15 Ruder MA, Winston SA, Davis JC, Abbott JA, Eldar M, Scheinman MM. Arrhythmogenic right ventricular dysplasia in a family. $A m \mathcal{f}$ Cardiol 1985;56:799-800.

16 Gussenhoven WJ, Spitaels SEC, Bom N, Becker AE. Echocardiographic criteria for Ebstein's anomaly of tricuspid valve. $B r$ Heart $\mathcal{F}$ 1980;43:31-7.

17 Smith WM, Gallagher JJ, Kerr CR, et al. The electrophysiologic basis and management of symptomatic recurrent tachycardia in patients with Ebstein's anomaly of the tricuspid valve. Am $\mathcal{F}$ Cardiol 1982;49:1223-34. 